\title{
Taxonomic Relationships of Cryptococcus and Tremella Based on Fatty Acid Composition and Other Phenotypic Characters
}

\author{
By E. J. SMIT, ${ }^{1 *}$ J. L. F. KOCK, ${ }^{2}$ J. P. J. VAN DER WESTHUIZEN ${ }^{1}$ \\ AND T. J. BRITZ ${ }^{2}$ \\ ${ }^{1}$ Department of Dermatology, Mycology Section, Medical Faculty, and ${ }^{2}$ Department of \\ Microbiology, PO Box 339, University of the Orange Free State, 9300 Bloemfontein, \\ Republic of South Africa
}

(Received 12 January 1988; revised 21 June 1988)

\begin{abstract}
The cellular long-chain fatty acids present in 33 strains, representing 15 species of Cryptococcus, and 4 species of Tremella, were determined by gas chromatography. According to the relative amounts of fatty acid methyl esters, the Cryptococcus species studied were divided into four main groups. Possible relationships between species representing the two genera are presented in a new model, where cellular long-chain fatty acid compositions and other phenotypic characteristics are included.
\end{abstract}

\section{INTRODUCTION}

Cellular long-chain fatty acids have been found in all bacteria (Tornabene, 1985) and bacterial lipid analyses are now well established in the taxonomy of these organisms (Shaw, 1974; Lechavalier, 1977; Minnikin et al., 1978; Goodfellow \& Minnikin, 1982; Collins et al., 1982; Bousfield et al., 1983). However, the first attempt to associate lipid composition with taxonomic classification was made by Abel et al. (1963), who illustrated that qualitative fatty acid analyses were useful for distinguishing between heterogeneous bacteria. Primary fatty acids, ranging from $\mathrm{C}_{14}$ to $\mathrm{C}_{20}$, have been detected in ascomycetous yeasts and have been used in the classification and identification of these organisms (Cottrell et al., 1985; Kock et al., 1986; Viljoen et al., 1986) as well as for the basidiomycetous yeasts (Smit et al., 1987a, b; van der Westhuizen et al., 1987a, b).

Since species of the genera Tremella and Cryptococcus synthesize starch and polymers consisting of D-mannose, D-xylose and D-glucuronic acid, and are morphologically similar, Slodki et al. (1965) suspected a phylogenetic relationship between them. Similarity of assimilation patterns also indicated that $C$. laurentii and its morphological varieties might be closely related to $T$. enchephala and T. aurantia (Slodki et al., 1965). They concluded that some species of Cryptococcus may represent one or more stages of the life cycle of some species of Tremella.

This report presents the results of long-chain fatty acid analyses on 33 strains representing 15 species of Cryptococcus and 4 species of Tremella. Comparisons have been made between their phenotypic characteristics and their long-chain fatty acid compositions.

\section{METHODS}

Strains. Cultures used in this study are given in Table 1 ; they were supplied by the Centraalbureau voor Schimmelcultures, Yeast Division, Delft, The Netherlands (CBS) and Professor F. Oberwinkler, Lehrstuhl Spezielle Botanik, University of Tübingen, FRG (FO).

Abbreviation: FAME, fatty acid methyl ester. 
Long-chain fatty acid analyses. The methods used for cultivation of strains and long-chain fatty acid analyses were as described previously (Smit et al., 1987 b). Comparative retention times of known standard methyl esters of $\mathrm{C}_{14: 0}$ (myristic acid), $\mathrm{C}_{16: 0}$ (palmitic acid), $\mathrm{C}_{16: 1}$ (palmitoleic acid), $\mathrm{C}_{17: 0}$ (margaric acid), $\mathrm{C}_{17: 1}$ (iso-margaric acid), $C_{18: 0}$ (stearic acid), $C_{18: 1}$ (oleic acid), $C_{18: 2}$ (linoleic acid), $C_{18: 3}$ (linolenic acid), and $C_{20: 0}$ (arachidic acid) were used as a basis for the identification of the fatty methyl esters. Relative amounts of the fatty acids present in the strains were calculated by integration of the respective methyl ester peak areas.

Phenotypic characteristics. Characteristics were determined as described by Rodriques de Miranda (1984). The following characters were used: pigmentation of culture; growth at $37^{\circ} \mathrm{C}$; starch formation; and assimilation of nitrate, erythritol, melibiose, raffinose, sucrose, lactose, soluble starch, maltose, L-rhamnose, citric acid, glucono$\delta$-lactone, galactose, succinic acid, sodium glucuronate, D-mannitol, ribitol, D-ribose, L-arabinose, D-xylose, trehalose, cellobiose and inositol.

Phenotypic similarities. Analyses were done by comparing groups of up to 33 strains. Both matched and unmatched pairs were equally weighted, using the simple matching coefficient of association of Sokal and Michener (Sokal \& Sneath, 1963). A dendrogram depicting phenotypic similarities (Fig. 1) was prepared by arranging species in clusters, by means of single linkage analyses (Sokal \& Sneath, 1963).

\section{RESULTS AND DISCUSSION}

The results of fatty acid analyses were reproducible when the strains were cultivated in triplicate (Table 1). The fatty acid methyl ester (FAME) profiles can be arranged into four groups. Group I was characterized by a higher mean percentage of $\mathrm{C}_{18: 1}(45 \% \pm 2.5 \%)$ and a lower mean percentage of $\mathrm{C}_{18: 2}(28.9 \% \pm 5 \cdot 67 \%)$ and the presence of $\mathrm{C}_{18: 3}(2.52 \% \pm 1.21 \%)$. Group II comprised strains that also produced $\mathrm{C}_{18: 3}(4.05 \% \pm 3 \cdot 12 \%)$ but had a higher mean percentage of $\mathrm{C}_{18: 2}(38.57 \% \pm 9.03 \%)$ than $\mathrm{C}_{18: 1}(27.26 \% \pm 5.02 \%)$. Groups III and IV comprised strains in which very little or no trace of $\mathrm{C}_{18: 3}$ could be detected under the experimental conditions. Strains representing group III were characterized by a lower mean percentage of $\mathrm{C}_{18: 1}$ and a higher mean percentage of $\mathrm{C}_{18: 2}$, when compared to group IV (Fig. 1, Table 1).

Within Cryptococcus, fatty acid compositions were largely species specific. With few exceptions, strains of the same species contained similar long-chain fatty acid compositions and could be grouped together (Fig. 1). C. macerans CBS 2206 and CBS 2425 were allocated to Group I; $C$. ater CBS 4685 and CBS 5809 were both in group II; $C$. neoformans CBS 132, CBS 879 and CBS 5474 were in Group III; and C. hungaricus CBS 4214 and CBS 5124 and C. terreus CBS 1895 and CBS 6517 were all in group IV. Kwon-Chung (1975) proposed the new genus Filobasidiella as the perfect state of $C$. neoformans and it is also interesting to note that FAME profiles obtained for several strains of $F$. neoformans (Smit et al., 1987a) were similar to those found for $C$. neoformans.

Concerning the exceptions, C. albidus var. albidus CBS 1929 was in group II whereas $C$. albidus var. albidus CBS 142, C. albidus var. diffluens CBS 160 and C. albidus var. aerius CBS 155 were all in Group III. Phaff \& Fell (1970) disassociated the variety diffluens (isolated from nail material) from the variety albidus, using its inability to assimilate lactose as the sole criterion. This variety was rejected by Rodriques de Miranda (1984) because of the vagueness of the criterion used by Phaff \& Fell (1970). The FAME profile of the strain CBS 160 of the variety diffluens showed similarities to the profile found for the variety albidus strain CBS 142, which strengthens Rodriques de Miranda's argument to reject the variety diffluens. Although there are several characteristics by which the variety aerius can be distinguished from albidus, the main physiological characteristic used is the consistent inability of the variety aerius to form starch and to grow at temperatures above $30^{\circ} \mathrm{C}$. Notwithstanding these facts, the FAME profile of the strain CBS 155 of the variety aerius proved to be very similar to that found for strains CBS 142 and CBS 160 , showing that this strain at least shares a very close relationship with the others. Strain CBS 1929 had a markedly different FAME profile when compared to the other strains of C. albidus, showing a high relative percentage of $\mathrm{C}_{18: 3}(7 \cdot 45 \%)$. This is inexplicable at this stage and further studies seem necessary.

Further anomalies were seen for C. laurentii CBS 5595, CBS 942, CBS 139 and CBS 2174. According to our study all the strains representing $C$. laurentii exhibited similar FAME profiles 


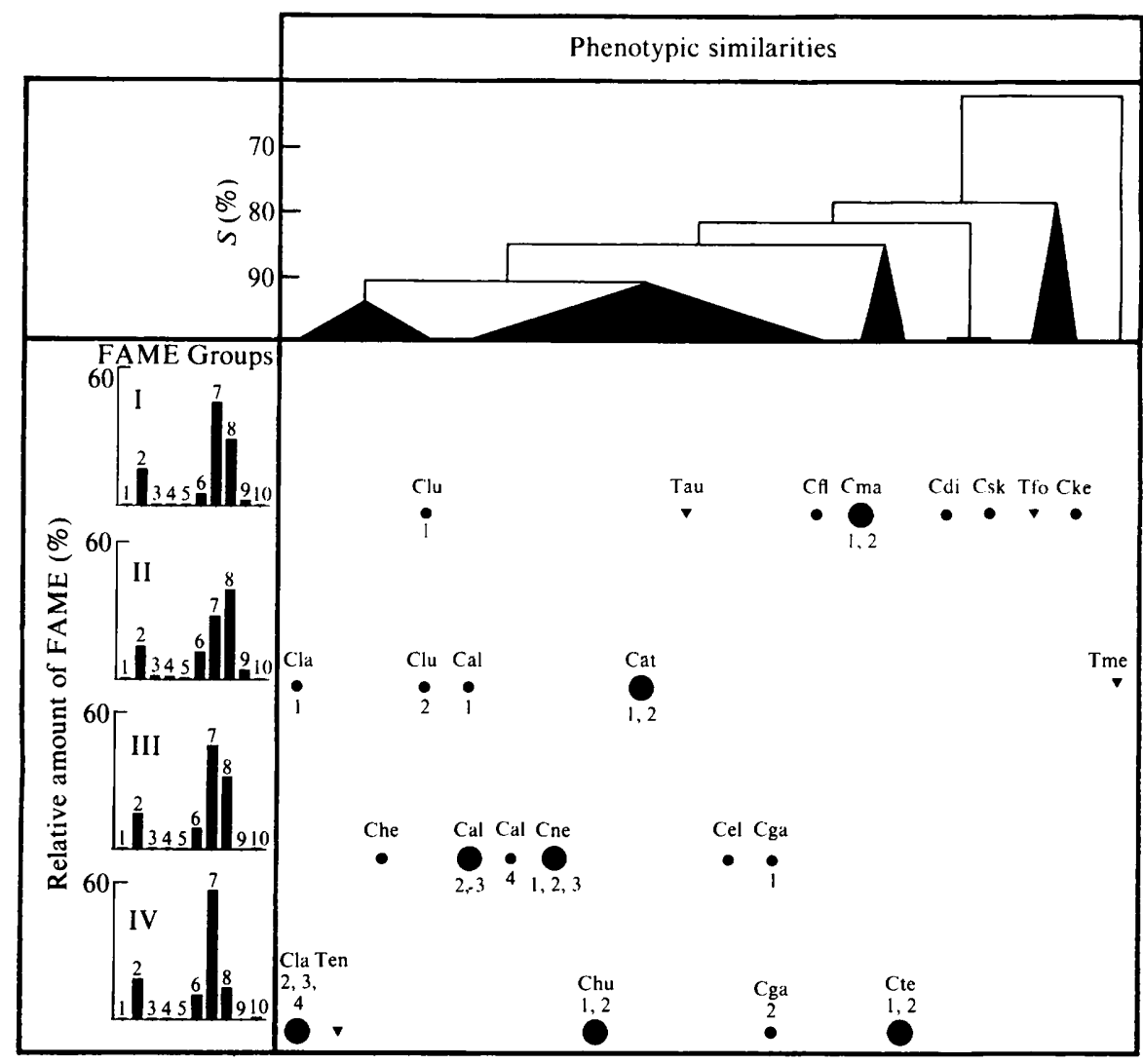

Fig. 1. Relationships between species representing the genera Cryptococcus and Tremella, arranged according to long-chain fatty acid compositions (vertical axis, left; the histograms show the percentage fatty acid composition for each group) and phenotypic similarities (horizontal axis, top). The species are positioned according to the results indicated on these axes. Key to organisms: Cal 1, 2, 3 and 4, $C$. albidus CBS 1929, 142, 160 and 155, respectively; Cat 1 and 2, C. ater CBS 4685 and 5809, respectively; Cdi, C. dimennae CBS 5770; Cel, C. elinovii CBS 7051 ; Cfl, C. flavus CBS 331; Cga 1 and 2, C. gastricus CBS 1927 and 7016, respectively; Che, $C$. heveanensis CBS 569; Chu 1 and 2, C. hungaricus CBS 4214 and 5214, respectively; Cke, C. kuetzingii CBS 2289; Cla 1, 2, 3 and 4, C. laurentii CBS 5595, 942, 139 and 2174, respectively; Clu 1 and 2, C. luteolus CBS 4937 and 943, respectively; Cma 1 and 2, C. macerans CBS 2206 and 2425, respectively; Cne 1, 2 and 3, C. neoformans CBS 132, 879 and 5474, respectively; Csk C. skinneri CBS 5029; Cte 1 and 2, C. terreus CBS 1895 and 6517, respectively; Tau, $T$. aurantia FO 31861; Ten, $T$. encephala FO 23371; Tfo, $T$. foliacae FO 25113; Tme, $T$. mesenterica FO 25145. Key to FAMEs: $1, \mathrm{C}_{14: 0} ; 2, \mathrm{C}_{16: 0} ; 3, \mathrm{C}_{16: 1} ; 4, \mathrm{C}_{17: 0} ; 5, \mathrm{C}_{17: 1} ; 6, \mathrm{C}_{18: 0} ; 7, \mathrm{C}_{18: 1} ; 8, \mathrm{C}_{18: 2} ; 9$, $\mathrm{C}_{18: 3} ; 10, \mathrm{C}_{20: 0}$.

except strain CBS 5595 (Table 1). It is therefore clear that this species does not seem to be homogeneous as proposed by Rodriques de Miranda (1984).

Although $T$. foliacae showed a FAME profile similar to $C$. kuetzingii, the fact that their phenotypic similarity is only $79 \%$ probably denotes that they are not in fact all that closely related. C. luteolus CBS 943, in group II, C. luteolus CBS 4937 in group I, C. gastricus CBS 7016 in group IV and C. gastricus CBS 1927 in group III also represent exceptions. In the case of $C$. gastricus the two strains studied differed significantly only in their $C_{18: 1}$ to $C_{18: 2}$ ratio, but were otherwise very similar. C. luteolus CBS 943 and CBS 4937 differed greatly in their relative percentage $\mathrm{C}_{18: 0}(2 \cdot 60 \%$ for CBS 4937 and $21.64 \%$ for CBS 943$)$, at present however, there is no explanation for this observation. 


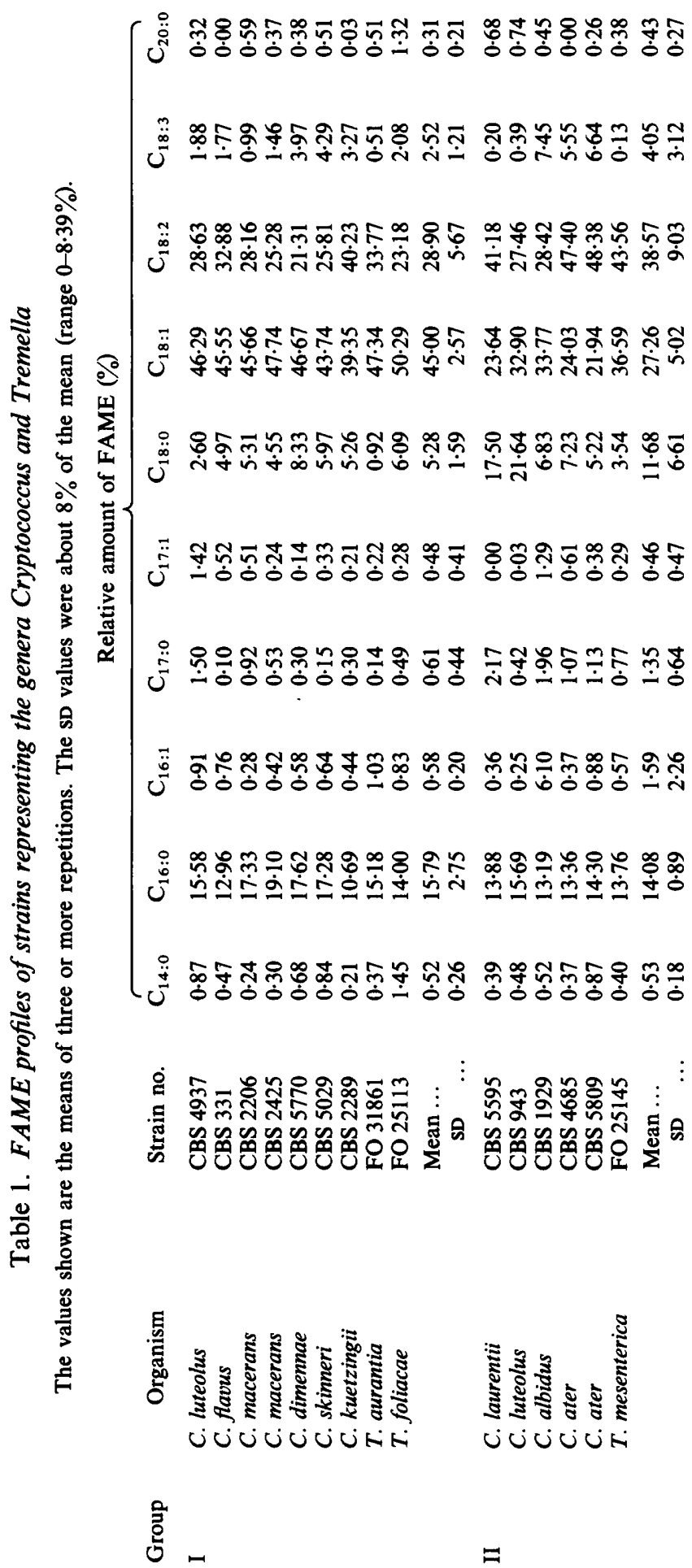




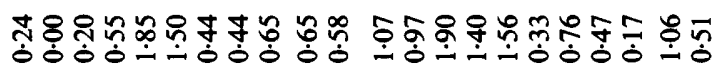

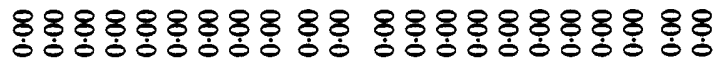

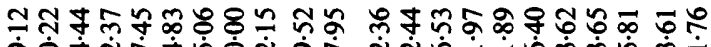

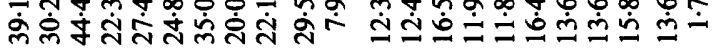

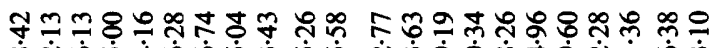

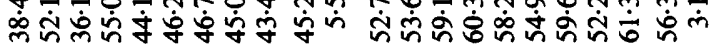

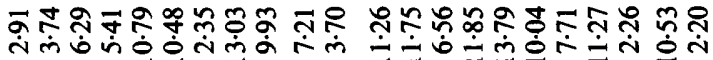

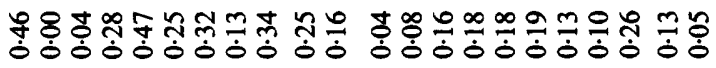

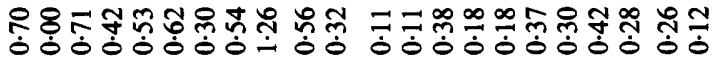

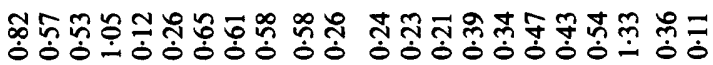

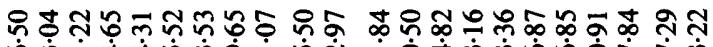

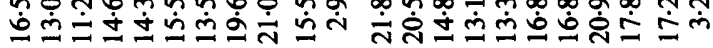

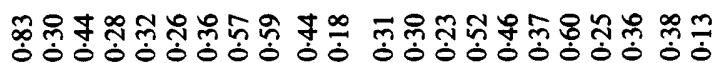

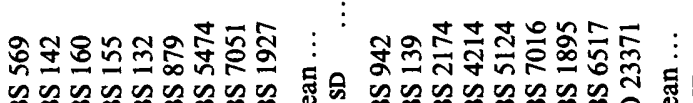

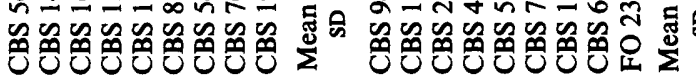

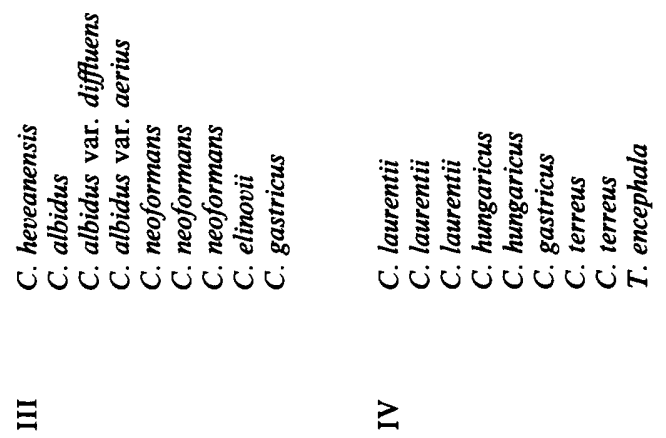


The organism described in 1921 by Groenewege as Torula heveanensis and assigned to $C$. laurentii var. magnus by Lodder \& Kreger-van $\mathrm{Rij}$ (1952) was also studied by Baptist \& Kurtzman (1976). They found that strain Y-1510 of Torula heveanensis was different from both $C$. laurentii var. magnus and $C$. laurentii var. laurentii and could not be considered an additional variety of $C$. laurentii. They therefore proposed a new species, $C$. heveanensis, with the culture originally described as Torula heveanensis NRRL Y-1510 (CBS 569) as the type strain. Our results (Fig. 1., Table 1) show that the FAME profile of $C$. heveanensis CBS 569 and C. laurentii also differed significantly.

On the basis of assimilation patterns, Slodki et al. (1965); Slodki \& Wickerham (1966) suggested that $C$. laurentii might be closely related to $T$. encephala and $T$. aurantia. Kurtzman (1973), however, was unsuccessful in mating sexually reactive isolates of $C$. laurentii with those of Tremella species, while different enzyme patterns were found for T. encephala, T. aurantia and C. laurentii (Baptist \& Kurtzman, 1976). This was criticized by Phaff (1984) for including too few enzymes, making interpretation of the results quite subjective and sensitive to the effects of population variation.

Our results show that $T$. encephala FO 23371 appears to be closely related to $C$. laurentii, while T. aurantia FO 31861 exhibited a different FAME profile. It would thus seem that the suggestion of Slodki et al. (1965), that a possible taxonomic relationship between certain Tremella and Cryptococcus species exists, may have merit after all. Polyacrylamide gel electrophoresis of total cell proteins is currently being used to introduce a further taxonomic character, to evaluate the results so far obtained.

According to our results the following conclusions can be drawn. The identification of individual Cryptococcus species, using long-chain fatty acid composition as the sole parameter, does not seem viable but distinct groupings of the FAME profiles were evident. For example, with few exceptions, strains of the same species of Cryptococcus showed similar FAME profiles. Secondly, based on the similarity of their FAME profiles $C$. albidus var. aerius and C. albidus var. diffluens seem to share a very close relationship with $C$. albidus var. albidus; this is in accordance with the proposal of Rodriques de Miranda to reject the variety diffluens. Thirdly, the significant difference in the FAME profile of one of the $C$. laurentii strains may imply that this species is not homogeneous. Finally, considering both long-chain fatty acid composition and phenotypic characteristics, $T$. encephala appears to be closely related to $C$. laurentii, while $T$. aurantia, thought to be closely related to C. laurentii (Slodki et al., 1965), seems to differ significantly.

We would like to thank Miss G. M. van Wyk and S. M. Watkins for technical assistance and Mr P. J. Botes for assistance with the GC analyses.

\section{REFERENCES}

Abel, K., Schmetzing, H. \& Peterson, J. I. (1963). Classification of micro-organisms by analysis of chemical composition. I. Feasibility of utilizing gas chromatography. Journal of Bacteriology 85, 10391044.

Baptist, J. N. \& Kurtzman, C. P. (1976). Comparative enzyme patterns in Cryptococcus laurentii and its taxonomic varieties. Mycologia 68, 1195 1203.

Bousfield, I. J., Smith, G. L., Dando, T. R. \& HobBs, G. (1983). Numerical analysis of the total fatty acid profiles in the identification of coryneform, nocardioform and some other bacteria. Journal of General Microbiology 129, 375-394.

Collins, M. D., Goodfellow, M. \& Minnikin, D. E. (1982). A survey of the structure of mycolic acids in Corynebacterium and related taxa. Journal of General Microbiology 128, 129-149.
CotTrell, M., KoCK, J. L. F., LATEGan, P. M., Botes, P. J. \& BRITZ, T. J. (1985). The long-chain fatty acid composition of species representing the genus Kluyveromyces. FEMS Microbiology Letters 30, 373376.

GoOdFELlow, M. \& MinNikin, D. E. (1982). Introduction of the coryneform bacteria. In The Prokaryotes: a Handbook of Habitats, Isolation and Identification of Bacteria, pp. 1811-1826. Edited by M. P. Starr, H. Stolp, H. G. Truper, A. Balows \& H. G. Schlegel. Berlin: Springer.

Kock, J. L. F. \& Lategan, P. M. (1986). A rapid method to differentiate between four species of the genus Kluyveromyces. Journal of Microbiological Methods 4, 299-302.

KuRTZMAN, C. P. (1973). Formation of hyphae and chlamydospores by Cryptococcus laurentii. Mycologia 65, 388-395. 
Kwon-Chung, K. J. (1975). A new genus Filobasidiella, the perfect state of Cryptococcus neoformans. Mycologia 67, 1197-1200.

LeCHEVALIER, M. P. (1977). Lipids in bacterial taxonomy - a taxonomists view-point. CRC Critical Reviews in Microbiology 5, 109-210.

LODDER, J. \& KREGER-VAN RIJ, N. J. W. (1952). The Yeasts, a Taxonomic Study. Amsterdam: North Holland Publishing Co.

Minnikin, D. E. Collins, M. D. \& Goodfellow, M. (1978). Lipid composition in the classification of coryneform and related taxa. In Coryneform Bacteria, pp. 85-160. Edited by I. J. Bousfield \& A. G. Callely. London: Academic Press.

PHAFF, H. J. (1984). DNA, enzymes and cell walls. In: The Yeasts: a Taxonomic Study, 3rd edn, pp. 17-21. Edited by N. J. W. Kreger-van Rij. Amsterdam: Elsevier.

PhafF, H. J. \& Fell, J. W. (1970). The Genus Cryptococcus Kützing, emend., pp. 1088-1145. Amsterdam: North Holland Publishing Co.

RodriQues de Miranda, L. (1984). Genus 5. Cryptococcus Kützing, emend. In The Yeasts: a Taxonomic Study, 3rd edn, pp. 845-872. Edited by N. J. W. Kreger-van Rij. Amsterdam: Elsevier.

SHAw, N. (1974). Lipid composition as a guide to the classification of bacteria. Advanced and Applied Microbiology 17, 63-108.

SLODKI, M. E. \& WickerhaM, L. J. (1966). Extracellular polysaccharides and classification of the genus Lipomyces. Journal of General Microbiology 42, 381-385.

SLODKI, M. E., Wickerham, L. J. \& Bandoni, R. J. (1965). Extracellular heteropolysaccharides from Cryptococcus and Tremella: a possible taxonomic relationship. Canadian Journal of Microbiology 12, 489-494.

SMIT, E. J., Kock, J. L. F., VAN DER WesthUIZEN, J. P. J. \& LATEGAN, P. M. (1987a). The long-chain fatty acid composition of the two varieties of Filobasidiella neoformans. Systematic and Applied Microbiology 10, 28-30.

SMIT, E. J., Kock, J. L. F., van DER Westhuizen, J.P. J. \& LATEGAN, P. M. (1987b). A yeast identification method: The influence of culture on the cellular longchain fatty acid composition of three selected Basidiomycetous yeasts. Systematic and Applied Microbiology 10, 38-41.

Sokal, R. R. \& Sneath, P. H. A. (1963). Principles of Numerical Taxonomy, pp. 290-317. London: W. H. Freeman.

TORNABENE, T. G. (1985). Lipid analysis and the relationship to chemotaxonomy. Methods in Microbiology 18, 209-221.

VILJOEN, B. C., Kock, J. L. F. \& LATEGAN, P. M. (1986). Long-chain fatty acid composition of selected genera of yeasts belonging to the Endomycetales. Antonie van Leeuwenhoek 52, 45-51.

VAN DER Westhuizen, J. P. J., Kock, J. L. F., SMit, E. J. \& LATEGAN, P. M. (1987a). The value of longchain fatty acid composition in the identification of species representing the Basidiomycetous genus Rhodosporidium Banno. Systematic and Applied Microbiology 10, 31-34.

VAN DER Westhuizen, J. P. J., Kock, J. L. F., SMit, E. J. \& Lategan, P. M. (1987b). The long-chain fatty acid composition of species representing the genus Rhodotorula Harrison. Systematic and Applied Microbiology 10, 35-37. 